\title{
Percentage Food Eaten Scale
}

National Cancer Institute

\section{Source}

National Cancer Institute. Percentage Food Eaten Scale. NCI Thesaurus. Code $C 131958$.

A scale for the subjective scoring of percentage of food eaten that ranges from $0 \%$ :

None to $100 \%$ : All of my food. 